\title{
Migrant tuberculosis screening in the EU/ EEA: yield, coverage and limitations
}

\author{
E. Klinkenberg*\#", D. Manisseroø, J.C. Semenzađ and S. Verver*,\#
}

ABSTRACT: A systematic literature review was performed with the objective of assessing the effectiveness of tuberculosis (TB) screening methods and strategies in migrants in European Union/European Economic Area (including Switzerland) countries.

Extracted data on yield and coverage were used as indicators of effectiveness. Reported yields varied considerably between studies and countries. Considering only the 14 studies representative of national screening programmes, a median yield of TB disease of $0.18 \%$ (interquartile range $0.10-0.35 \%)$ was reported.

The data did not indicate differences in effectiveness between the three main strategies: 1) screening at port of entry; 2) screening just after arrival in reception/holding centres; and 3) screening in the community following arrival in European Union countries. The variation seen probably reflects variation in risk factors for TB, in particular the composition of the migrants entering the country.

Recommendations include the need for improved data for guiding the optimal frequency and duration of screening; assessment and improvement of cost-effectiveness; access to healthcare for migrants, including illegal migrants; ensuring a continuum of care for those screened; and consideration of screening for latent TB infection with caution. Finally, screening should be a component of a wider approach, rather than a stand-alone intervention.

KEYWORDS: Coverage, migrant, screening, systematic review, tuberculosis, yield

$n$ most parts of the European Union (EU), particularly in low-incidence countries, the decline in tuberculosis (TB) incidence has slowed. This trend is partly related to immigration from countries in Africa, Southeast Asia, parts of Latin America and former Eastern Europe. In these countries, TB remains more widespread than in most EU countries, and far less controlled. Within the EU, the percentage of foreign-born cases among overall $\mathrm{TB}$ cases ranges $0-82$, with a mean of 20 [1]. In most low-incidence countries, this percentage has been increasing since the late 1990s [2]. Furthermore, TB among the foreign-born tends to affect the younger age cohorts [3].

Factors influencing TB incidence among migrants are country of origin, age, sociodemographic factors, exposure and travel to country of origin, access to care, drug resistance and immune incompetence [4]. Three main epidemiological aspects are associated with the high incidence of TB among migrants after settling in low-incidence countries [4]. 1) Reactivation of prior TB infections.
Several studies suggest that the majority of migrant cases occur due to reactivation of latent infection $[5,6] .2)$ Recent TB infection or reinfection due to travel to the home country [7-9]. 3) Recent infection or reinfection within the new country that is related to local exposure and social mixing [6, 10-12].

Screening for TB is one of the interventions often performed to control TB among new entrants in low-incidence countries. Screening focuses on foreign-born persons who apply for immigration or who have recently arrived for two main reasons: 1) TB rates are highest among recent arrivals; and 2) the application for immigration or long-term residence provides a unique opportunity for screening and is one of the few reliable points of contact with new entrants [4].

Different screening systems for migrants are employed in the various EU countries. A study in 2003 into screening programmes in the EU showed that half of the 26 countries that reported data had no specific TB screening programme [13].

\section{AFFILIATIONS}

${ }^{*}$ KNCV Tuberculosis Foundation, The Hague,

${ }^{\#}$ Dept of Infectious Disease, Tropical Medicine and AIDS, Center for Infection and Immunity Amsterdam, Academic Medical Center, University of Amsterdam, Amsterdam, The Netherlands.

-European Centre for Disease Prevention and Control, Stockholm, Sweden.

\section{CORRESPONDENCE}

D. Manissero

Scientific Advice Unit European Centre for Disease

Prevention and Control

Tomtebodavägen $11 \mathrm{~A}$

S-171 83 Stockholm

Sweden

E-mail: Davide.Manissero@

ecdc.europa.eu

Received:

March 062009

Accepted after revision:

April 142009 
Of the 13 that had a screening programme, three conducted screening at the port of entry and nine at other centres after arrival. At that time, no EU country conducted pre-entry screening.

The comparative effectiveness of the different screening strategies has not been previously evaluated. We, therefore, conducted a systematic literature review with the purpose of: 1) assessing the effectiveness (coverage and yield) of various screening strategies and methods of identifying active TB among new entrants to the EU/European Economic Area (EEA) member states (including Switzerland for the purposes of the present review); and 2) comparing the EU/EEA findings to those of non-EU low-incidence countries. The proposed approach is a unique comparative analysis of the effectiveness of various screening strategies not previously attempted.

Screening in the EU focuses on active disease. Latent TB infection (LTBI) yield was reported less frequently, which made comparison of studies difficult. Therefore, the present article focuses on the effectiveness of screening for TB disease.

\section{METHODS}

\section{Literature search}

Online reference databases (PubMed, The Cochrane Library, MEDLINE, EMBASE and Scopus) were searched using keywords combinations of "(im)migrant" (or "asylum seeker(s)" or "refugee" or "foreign born") with "screening (policy)" either alone or in combination with "X-ray" (or "tuberculin skin test") and "port of entry" (or "visa" or "arrival"). In addition, the library database of the KNCV Tuberculosis Foundation was searched. Articles published up to February 2008 were included.

Only articles for which at least an English abstract was available were included. After scanning through titles and abstracts, relevant full articles were obtained. Articles aged $>10$ yrs (i.e. from before 1998) were excluded unless they appeared highly relevant, i.e. reporting yield of screening in an EU/EEA country or specifically discussing EU policies as regards screening. After thorough screening of abstracts and, where available, full articles, studies were given a classification of A, B, C or D, developed for the present systematic review, as follows. A: randomised comparative studies, in which intervention and control are randomly assigned to an individual to undergo a certain screening programme. B: studies reporting yield and/or coverage of screening programmes for new entrants or populations, with the majority being migrants by any strategy or any method. C: studies reporting on screening in relation to migrants but not reporting yield/coverage data. Studies on risk factors for TB in migrants, comparative studies on screening diagnostic tools, studies on treatment outcome and adherence, studies modelling screening outcomes and studies on DNA fingerprinting related to migrants/the foreign born were included. D: articles/reports discussing current screening programmes, screening policies and strategies of screening at country or regional level in relation to public health or regional level epidemiology, as well as studies on the cost-effectiveness of screening strategies.

Owing to the nature of the studies, it was not possible to use more standardised classifications, such as the Scottish Intercollegiate Guideline Network criteria [14].

\section{Definitions}

A TB case was defined as a bacteriological or clinical diagnosis of TB based on intention to treat. Not all studies reported criteria and definitions clearly; therefore, hereafter TB cases refer to TB cases as reported by the authors, which implies TB cases detected through screening by chest radiography.

Coverage was defined as the percentage of the target group to be screened that was indeed screened.

TB yield: the various articles used different definitions for yield. Most articles did not provide sufficient detail to recalculate TB yield to a standardised definition. Therefore, yield was used as reported by the authors and hereafter yields refer to such.

Screening strategy was defined as the set of regulatory actions and regulations that act to regulate the screening of individuals for the presence of a disease.

In order to classify screening strategies, six categories were used as follows. 1) Pre-entry/pre-migration screening: screening before arrival in the country of destination. 2) Port of arrival screening: screening at the airport/harbour upon arrival. 3) Reception/holding/transit centre screening: screening at the reception or holding centre shortly after arrival in the country. In most countries, asylum seekers are referred to special holding/reception centres to await a decision on their immigration status. 4) Community post-arrival screening: screening at the community level after arrival, usually for migrants other than asylum seekers. 5) Occasional screening: screening of specific groups (migrant shelters or illegal migrants) in the community, e.g. during outbreaks. This is not part of a regular screening programme. 6) Follow-up screening: periodic followup screening after the initial entry screening.

Screening at the reception/holding centre, in the community following arrival and occasional screening all take place after arrival but have potentially different yields. Therefore, the different approaches were categorised separately.

Some screening programmes are voluntary, whereas others are mandatory. Even mandatory screening is often carried out without coercion. Compliance is ensured in several ways, i.e. the screening result is a requirement for a residence permit, access to healthcare or social benefits, or permission to work [4].

The definitions of migrant, asylum seeker, foreign-born citizen and illegal migrant of RIEDER et al. [15] were adopted.

Migrant: a foreigner legally admitted and expected to settle in a host country.

Asylum seeker: a person wishing to be admitted to a country as a refugee and awaiting decision on their application for refugee status under relevant international instruments.

Foreign-born citizen: a person who is a national of the state in which they are present but who was born in another country.

Illegal foreigner/migrant: a person whose entry, stay or work in a host country is illegal.

\section{Data extraction}

Data were extracted from the articles classified as A and B. No attempt was made to obtain original data. Articles classified as 
$\mathrm{C}$ and $\mathrm{D}$ were used for discussion of their findings. If more than one screening strategy was discussed in an article, or when data on asylum seekers and migrants were reported separately, a separate data record was extracted into the database for each type.

The present review focused on articles from EU/EEA countries, hereafter referred to as the EU. For comparison, data were also extracted from articles from non-EU countries. This was carried out for studies classified A and B from non-EU countries published since 2000. These data were used to assess whether or not there were differences between EU and non-EU countries in terms of the screening strategies used, and yield and coverage of screening obtained. They were also used for the discussion section, but did not form part of the main analysis.

Data extracted from studies on occasional screening were presented, but not included when stratifying the data by characteristics influencing screening coverage and yield (table 1) for reasons of comparability (see above).

Owing to the high variation and skewed distribution of data between studies, mean \pm SD was not an appropriate measure for comparison. Therefore, median and interquartile range (IQR) were used to compare yield and coverage between studies. Owing to the large variability seen between studies and limitation of the data, a meta-analysis of the effectiveness of different strategies was not possible. Therefore, no inference and heterogeneity index are given.

The focus of the present review was a comparison of the effectiveness of different screening methods in the EU. Since cost-effectiveness was not taken into account, effectiveness per se was difficult to judge. The comparison of the screening yield with background prevalence of the country of origin was judged unfeasible given the suboptimal reporting of the nationality of screened individuals in the studies included in the review.

\section{RESULTS}

\section{Literature search}

A total of 568 (nonduplicate) references were found using the search terms in the search engines, of which 345 were classified A, B, C and D (fig. 1). Only one article was classified as A [42], but, owing to the different nature of this article, these data were not used in the main analysis. Data records were extracted from the 49 articles from EU countries classified as B [12, 16-31, 33-41, 43-64]. Data from 11 of these were not included in the analysis as they had data ranges overlapping those of other included studies [45, 47, 48, 50, 53, 54, 56, 60-62, 65]. In such cases, the record with the widest data range (in time or geographically) was retained. Two articles reported only LTBI yield $[39,58]$. From the remaining 36 articles, 40 records were extracted, since two records were extracted from each of four articles [28, 30, 36, 41]. For the comparison with non-EU data, 15 records were extracted from 14 articles published after 2000 [66-79].

\section{Screening in the EU}

The extracted data from EU countries form the basis of the present systematic review. The extracted data covered 12 countries, 11 EU countries and Switzerland, which was included due to its comparability to the other countries in the region. All of the above-defined strategies were reported, except for pre-entry screening. The UK started implementing pre-migration screening in several countries in 2005, but no data were reported. All migrant screening programmes from these 12 countries reported the use of chest radiography to screen for active disease. This approach was applied using different guidelines, and sometimes in combination with different diagnostic tools, i.e. stepwise symptom screening or screening first for LTBI using the tuberculin skin test. Exact details of methods were not always clearly reported. Therefore, a meta-analysis and/or more in-depth analysis of the effectiveness of different methods was not possible.

\section{Overall yield and coverage of screening}

Data on coverage were not reported for all of the studies. Of the 42 records, only 22 reported coverage data [12, 17-23, 25, $26,30,33-36,40,41,46,49,52,57,59]$. Coverage ranged from $<20$ to almost $100 \%$. The lowest coverage was reported from a study in the port of arrival scheme in Hackney, UK [33]. The highest coverage, $99.8 \%$, was reported from screening of asylum seekers in Belgium [63]. 10 studies reported losses to follow-up, which varied widely, ranging 1.6-60.0\% (median 11.5\%; IQR 6.1-25.2) [18, 33-35, 39, 46, 49, 52, 55, 59].

\section{TABLE 1 Determinants of coverage and tuberculosis yield in 28 records from screening upon or just after arrival}

$\begin{array}{llll}\text { Records of coverage/ Subjects } n \quad \text { Coverage \% } & \text { Reported yield \% }\end{array}$

yield $n$

\begin{tabular}{|c|c|c|c|c|c|}
\hline \multicolumn{6}{|l|}{ Type of coercion } \\
\hline Mandatory & $12 / 21$ & $24156(12176-68122)$ & $90.6(70.2-95.7)$ & $0.28(0.10-0.42)$ & {$[12,16-32]$} \\
\hline Voluntary & $4 / 7$ & $2855(1121-4311)$ & $48.5(34.7-66.2)$ & $0.40(0.16-0.98)$ & [33-38] \\
\hline \multicolumn{6}{|l|}{ Type of migrant } \\
\hline Asylum seeker & $9 / 12$ & $17824(10331-33753)$ & $94.0(75.0-95.5)$ & $0.35(0.25-0.41)$ & $\begin{array}{c}{[12,16,18,22,25,26} \\
28,30,34,35,37,39,40]\end{array}$ \\
\hline Other migrant & $6 / 14$ & $5925(1431-36951)$ & $47.8(39.3-76.3)$ & $0.17(0.10-0.63)$ & {$[17,19-21,27-29,31-33,36,38,41]$} \\
\hline Migrants/asylum seekers & $1 / 2$ & 218565 (50748-386382) & 96.1 & $0.30(0.09-0.50)$ & {$[23,24]$} \\
\hline
\end{tabular}

Data are presented as median (interquartile range), unless otherwise indicated; the combination data (migrants/asylum seekers) represent two studies and so data are presented as median (range). Occasional screening and follow-up screening studies were not included. 


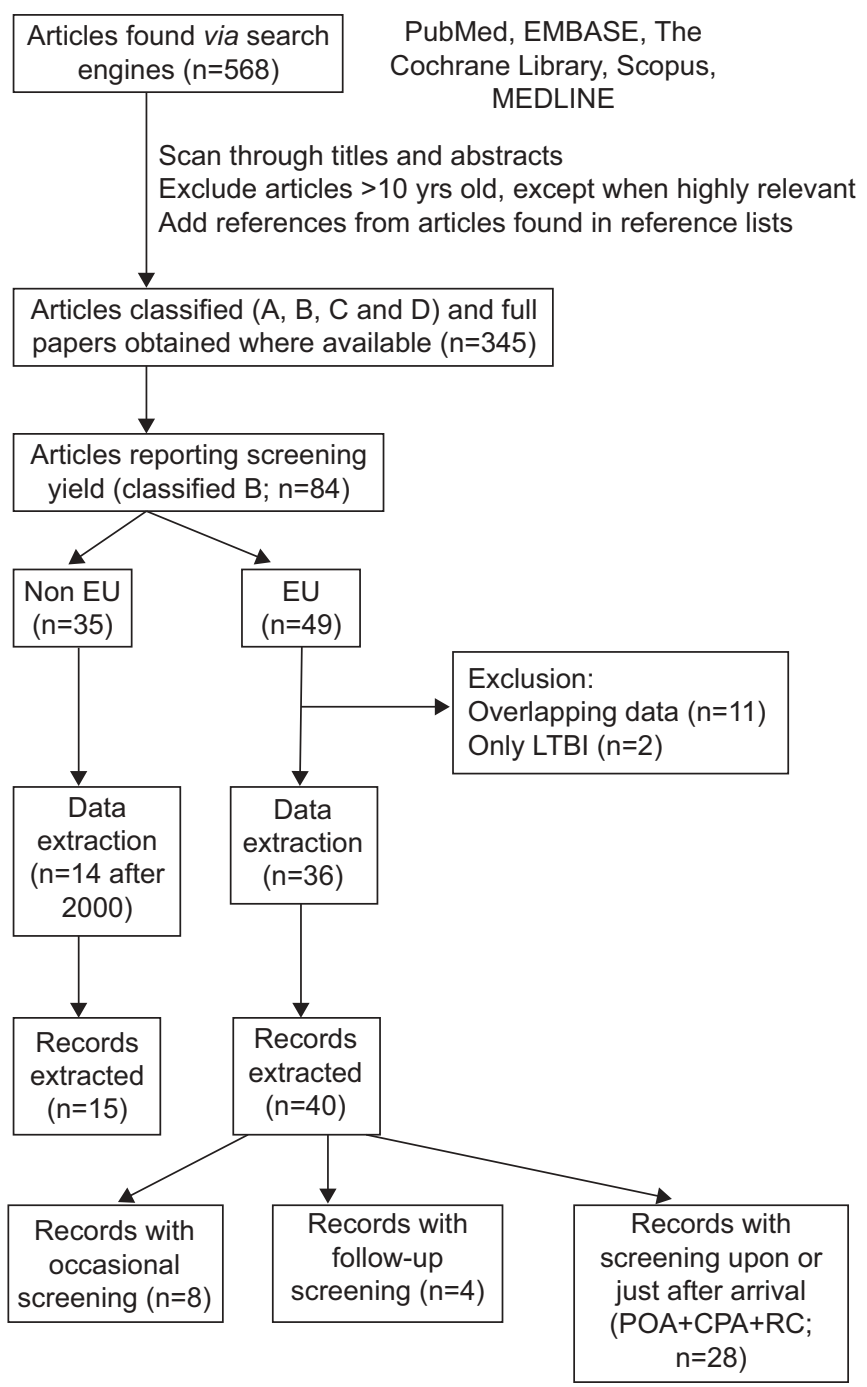

FIGURE 1. Flow diagram of selection process of articles included in the overview presented in the current review. EU: European Union/European Economic Area; LTBI: latent tuberculosis infection; POA: port of arrival; CPA: community postarrival screening; RC: reception/holding centre.

The overall yield of TB screening among the extracted data from the EU articles ranged $0.0-4.0 \%$, with a median yield of $0.35 \%$ (IQR $0.11-0.71 \%$ ) (table 2 ). The yield varied considerably between the different studies. The highest yield reported was $4.0 \%$, in an occasional screening study in Italy in a community of Senegalese migrants [52]. The highest yield obtained in a regular screening programme was $1.5 \%$, via the port of arrival scheme in Hackney (UK), where three cases of TB were detected among 199 people, although coverage was only $18.6 \%$ [33]. The lowest yield reported was in Greece at $0.0 \%$ among 1,727 persons in a report of screening of asymptomatic migrants applying for a residence permit [21]. When occasional and follow-up screening were not taken into account, the overall median yield reported was slightly lower at $0.30 \%$ (IQR $0.10-0.51 \%$ ). 10 studies differentiated between pulmonary and extrapulmonary TB. The majority of cases were pulmonary TB, with a median proportion of 91.6\% (IQR 87.2-93.9\%).

\section{Yield and coverage by screening strategy}

The reported coverage varied and was highest for screening at reception/holding centres (table 2). Only one study in the UK reported coverage for community post-arrival screening, which was very low at $18.6 \%$. The coverage of entry screening for the Netherlands is estimated to be $\sim 70 \%$ [41]. Screening at the port of arrival, in the reception/holding centre or in the community after arrival produced similar yields for TB disease (median $0.20-0.36 \%$, with overlapping IQR) (table 2). The lowest TB disease yields were reported for follow-up screening after the initial entry screening. A median yield of TB disease of $0.12 \%$ was reported for follow-up screening, with a median coverage of $46.5 \%$ (table 2). The highest yields, as well as high coverage, were reported from occasional screening studies, in which the median yield reported was $1.7 \%$, with a median coverage of $91.0 \%$.

Occasional screening does not form part of the regular screening programme and is used either for specific (highrisk) groups or on specific occasions. A study in Spain during a hunger strike among asylum seekers in churches reported a yield of $0.73 \%(n=546)$ [55]. During an outbreak of TB in migrant shelters in Paris, a yield of $1.72 \%(n=1,360)$ was reported [43]. Occasional screening studies have much lower sample sizes and are not directly comparable with studies reporting data from a national screening programme. Three studies report on screening of a specific group of refugees on or shortly after arrival, with a median yield of $0.72 \%$. Two were Kosovan refugees being screened upon arrival in Norway [57] and Ireland [59], and one reported on a cohort of Vietnamese refugees arriving in Denmark [44]. Only one study reported the yield of screening of illegal migrants. This was an occasional screening study in Italy, for which a yield of $0.65 \%$ was reported [49].

\section{Yield and coverage by country}

Of countries with a national screening programme, Belgium, Germany, the Netherlands, Switzerland and the UK, the extracted data showed similar ranges of TB screening yield, with median yields of $0.20-0.40 \%$ (table 3 ). Norway reported a lower yield at $0.11 \%$. Coverage varied but was reported to be $>90 \%$ in nearly all countries. The studies from Belgium and the UK reported much lower coverages of $\sim 55 \%$.

\section{Yield and coverage by other characteristics}

When screening was mandatory, a much higher coverage was reported than with voluntary screening (median coverage 90.6 and $48.5 \%$, respectively) (table 1). Median TB yield, however, seemed slightly lower in mandatory screening studies $(0.28$ versus $0.40 \%$ ), although the variation was large.

The median yield of screening of migrants reported was slightly lower than that of asylum seekers (0.17 and $0.35 \%$, respectively) (table 1), although large variation was seen, especially in the migrant group.

\section{Subsample of nationally representative studies}

When only large-scale studies reporting data on the whole or nearly the whole country, representative of the national screening programme, were compared and smaller studies were omitted, data from 14 studies remained (table 4 ) $[18,20$, 22-24, 26-28, 30-32, 41, 63, 64]. These studies had a median 
TABLE 2 Sample size, coverage and tuberculosis yield for different screening strategies in European Union countries

$\begin{array}{ccccc}\text { Records of } & \text { Subjects } n & \text { Coverage } \% & \text { Reported yield \% } & \text { [ref.] } \\ \text { coverage/yield } n & & \end{array}$

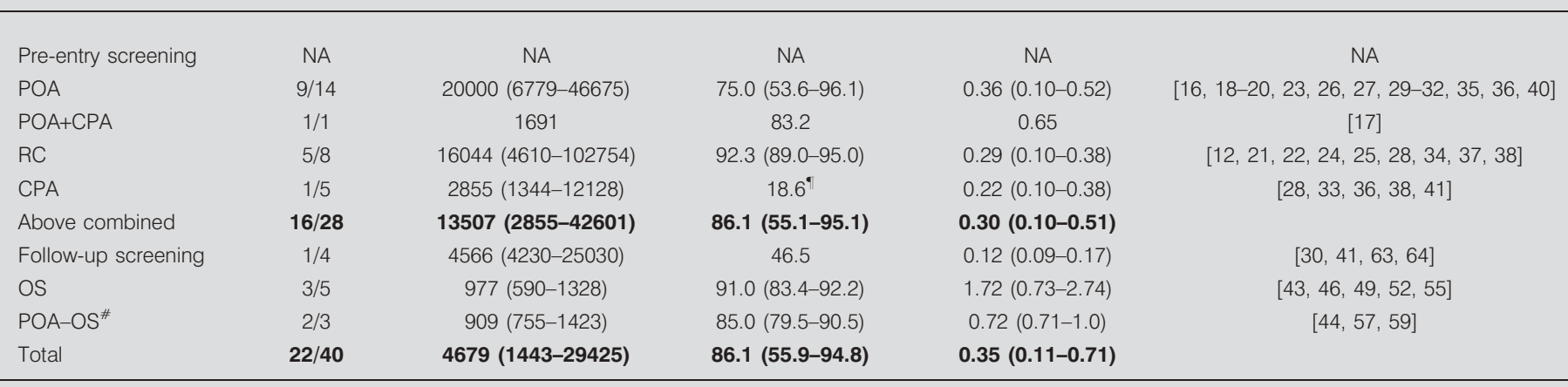

Data are presented as median (interquartile range), unless otherwise indicated. NA: not available; POA: port of arrival; CPA: community post-arrival screening (by invitation); RC: reception/holding centre; OS: occasional screening. ${ }^{*}$ : reports on screening of a specific group of refugees at or shortly after arrival; these studies were also considered occasional screening studies since they covered only a specific group of migrants; ${ }^{\natural}$ : data from one UK study, coverage of entry screening for the Netherlands is estimated to be $\sim 70 \%[41]$.

sample size of 42,036 (IQR 25,837-63,779) and reported a median yield of $0.18 \%(0.10-0.35 \%)$ and median coverage of $89.0 \%$ (76.2-95.9\%). These figures could be considered medians obtained from national migrant screening programmes in the EU setting.

When comparing the three main strategies within this group of 14 nationally representative studies (table 4), no strategy appears to be the most effective. The median coverage reported for screening at port of arrival was $92.4 \%$. The yield obtained among other migrants seemed slightly higher than among asylum seekers in these selected studies (0.25 versus $0.11 \%$ ), whereas coverage was higher among asylum seekers. Although the median yield $(0.30 \%)$ obtained by screening in the community after arrival seemed higher, only two studies were available, and only one of these had a yield higher than that of screening at port of arrival or reception/holding centre. Screening after arrival and in reception/holding centres both reported median yields of $0.18 \%$.

\section{Screening in non-EU countries}

For comparison, data were extracted from non-EU studies. The countries covered in the included studies were the USA, Canada, Australia and Japan. The sample sizes of the non-EU studies were smaller than those of the EU studies (median 1,444 versus 4,679 , respectively). Coverage was similar at $84.5 \%$ (IQR 70.2-94.7\%) in non-EU countries and 86.1\% (55.9-94.8\%) in EU countries. Overall, the median yield of screening seemed slightly higher in the non-EU studies, in which the median TB yield was $0.51 \%(0.17-1.23 \%)$, whereas this was $0.35 \%(0.11-$ $0.71 \%$ ) in the EU studies. No data were available on screening at port of arrival for the non-EU countries. The reported yield of screening in the community after arrival in non-EU countries was $0.31 \%(0.11-2.1 \%)$. For the non-EU countries, data on pre-entry screening were available. This screening strategy produced a high median yield of $1.21 \%(0.85-1.25 \%)$. However, data were only available from three studies that all concerned migrants entering from Asian countries. Two studies reported on pre-migration screening of USA-bound migrants from Vietnam $[66,80]$ and one on USA-bound migrants from Cambodia [66].

The coverage reported from studies on voluntary screening programmes was very similar in EU and non-EU countries, with a median coverage of 75.8 and $76.7 \%$, respectively. The reported coverage of mandatory screening programmes was slightly higher in non-EU countries, mainly due to the $100 \%$ coverage of pre-migration screening.

\section{DISCUSSION}

\section{Interpretation of findings}

Very few systematic evaluations of screening for active TB have been carried out. When examining the yield and coverage, indicators of effectiveness, of the different strategies in the EU, we found high variability. There was no indication of higher effectiveness in the EU countries of any of the three main strategies: 1) screening at port of entry; 2) screening just after arrival in reception/holding centres; and 3) community postarrival screening. If only the studies representative of national screening programmes (14 studies) were considered, a median TB disease yield of $0.18 \%$ (IQR $0.10-0.35 \%$ ) was reported. This is several-fold higher than the TB incidence rates in low-incidence countries, which are usually $<0.05 \%[1,2]$.

Outside the EU, screening yields for post-entry screening were similar. Non-EU countries also reported a fourth strategy, i.e. pre-entry screening, of which the reported yield seemed higher, with a median yield of $1.21 \%$. These reports were limited to prospective migrants from Asian countries to the USA and Australia.

The large variation found between studies, countries and over time probably reflects variation in the major risk factors, particularly the composition of the migrants entering the country [23, 67].

The higher yield reported among asylum seekers might be related to the difficult circumstances asylum seekers experience 
TABLE 3 Sample size, coverage and tuberculosis yield reported for entry screening in different European Union countries

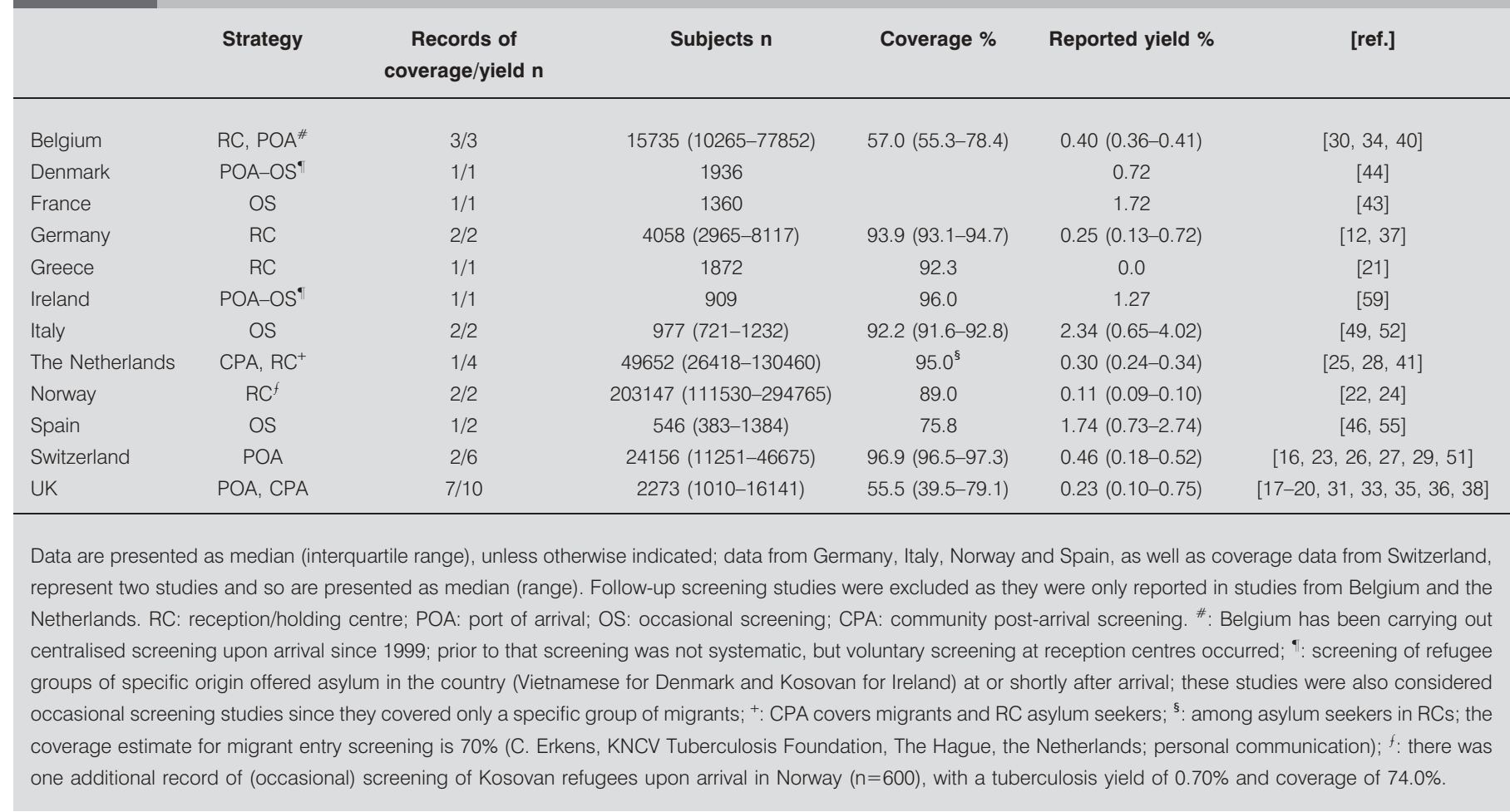

before arrival in the host country [68] and access to care within the host country $[69,70]$.

The results of the present systematic review suggest that the yields of screening for active TB are relatively low, particularly when compared to other types of active case-finding, such as contact tracing [45, 71, 72], and warrant consideration of screening as a component of a wider approach rather than as a stand-alone intervention.

Our systematic review revealed that, in addition to the regular screening programmes, some countries carry out occasional screening of specific high-risk groups or in specific circumstances (e.g. illegal migrants and outbreaks). These studies reported the highest yields, probably due to the specific conditions or groups targeted.
It is interesting that the present systematic review revealed that a mandatory approach to screening resulted in higher coverage but not necessarily a higher TB yield. This suggests that enforcing screening upon the migrant population might not have a public health benefit. Mandatory screening possibly increases the absolute number of cases detected since the overall number screened are increased. If screening is voluntary, people who feel ill may be more likely to enrol than people who do not feel ill, increasing the yield.

\section{Recent policy changes}

Several countries have recently adapted their national screening system, such as Switzerland [29] and the UK, or have called for a national screening system in publications, such as Italy and Spain $[5,55,73,74]$. As part of this project, a study has been

TABLE 4 Summary of sample size, coverage and yield for 14 selected national representative studies

\begin{tabular}{lcccccc} 
& $\begin{array}{c}\text { Records of } \\
\text { coverage/yield } \mathbf{n}\end{array}$ & Subjects $\mathbf{n}$ & Coverage \% & Reported yield \% & [ref.] \\
\hline POA & $4 / 10$ & $45800(25912-89509)$ & $92.4(85.5-96.2)$ & $0.18(0.09-0.35)$ & {$[18,20,23,24,26,27,30-32,63,64]$} \\
CPA & $0 / 2$ & $35374(30879-42401)$ & & $0.30(0.10-0.50)$ & {$[28,41]$} \\
RC & $1 / 2$ & $36740(33879-42601)$ & 77.30 & $0.18(0.10-0.26)$ & {$[22,28]$} \\
Immigrants & $4 / 6$ & $36326(30954-47964)$ & $76.2(70.2-81.9)$ & $0.25(0.15-0.34)$ & {$[20,27,28,31,32,41]$} \\
Asylum seekers & $2 / 6$ & $46675(25584-85166)$ & $92.6(90.8-94.4)$ & $0.11(0.08-0.24)$ & {$[18,22,26,28,30,63,64]$} \\
Combined & $1 / 2$ & $205269(114713-295826)$ & 97.6 & $0.25(0.17-0.33)$ & {$[23,24]$} \\
\hline
\end{tabular}

Data are presented as median (interquartile range), unless otherwise indicated; community post-arrival screening (CPA), reception/holding centre (RC) and combined data represent two studies and so are presented as median (range). POA: port of arrival. 
carried out to make an inventory of migrant screening policies in EU countries. This survey will be published separately.

\section{Limitations}

The present systematic review had some limitations. Not all studies clearly reported the criteria and definitions used, which made detailed comparison between studies impossible [4, 13, 75]. For example, definitions of TB differed; some studies reported only culture-confirmed cases, whereas others used intention to treat. The diagnostic tools used also varied between studies, countries and strategies. Although all reported programmes used chest radiography as a primary method of screening for active disease, its use and sometimes combination with other tools, such as symptom screening, differed. In addition, the lower age limit of the population targeted for radiographic screening ranged 4-15 yrs.

\section{Issues for consideration in the screening debate}

The following recommendations on migrant screening could form part of a strategy for improving TB control in Europe.

\section{Requirement for improved data}

There is a need for rational decision-making regarding the optimal frequency and duration of screening based on costeffectiveness analysis [50,67]. Other authors have previously reported that, out of $20 \mathrm{EU}$ countries with $\mathrm{TB}$ screening programmes for new entrants, only four were systematically collecting data [4]. The results of the present review also clearly indicate that systematic recording and reporting of screening performance must become a prerequisite for any screening programme in order to guide evidence-based decisions and support policies and be able to compare results across different member states. In particular, data on coverage and yield must be systematically collected and analysed using the same criteria. Evaluation of the recent changes in screening policy, as indicated above, will provide valuable information for screening programmes in the EU.

\section{Assessment and improvement of cost-effectiveness}

TB screening programmes are currently the subject of debate because of their costs and public health impact [11, 51, 76-79]. Recent analysis of the cost-effectiveness of screening programmes concluded that current radiographic screening programmes have minimal impact and are not cost-effective [81]. Such studies should also be performed in the European setting.

Screening large numbers of migrants requires substantial resources and it is suggested that it may be of more public health benefit to concentrate scarce resources on the early detection of TB through regular services, treatment completion and improving access to healthcare for migrants [82]. Better targeting of those with a high risk of developing active disease both at entry and thereafter is needed in order to increase yield and, therefore, cost-effectiveness.

Improvement of access, particularly for special groups

Improved access to care for migrants, and especially illegal migrants, is important for TB control [83]. There is a need for inclusion of groups that are currently not properly covered that are at higher risk of $\mathrm{TB}$, e.g. illegal migrants. It is a challenge to target this hidden population. Care should be taken that policies are not misused to enforce migration regulation by identification of illegal migrants. An anonymous screening system could be of value [84, 85].

\section{Assurance of continuum of care}

A good follow-up system is very important for all of the strategies in order to maximise the yield of the entry screening system. Proper follow-up is needed in order to minimise withdrawals during screening and to maximise coverage of the target group, as well as treatment adherence. Screening for active disease can only be beneficial for public health when treatment success rates are high. TB care should be offered integrated with other healthcare within the context of a holistic approach to ensure the health and well-being of new entrants.

\section{Consideration of $L T B /$ screening with caution}

Since not enough data on LTBI screening for proper comparison were available in the selected articles, LTBI screening could not be included in the main review. Although screening in the EU is focused on TB disease, in recent years, there have been calls for LTBI screening and provision of preventive treatment in order to eliminate TB [86-91]. Outside the EU, some migrants are screened for LTBI $[88,92,93]$. It has been suggested that the major potential benefit of entry screening is the detection of LTBI, but only if cases with latent infection receive and complete preventive therapy $[77,87]$. This would increase the expense and complexity of the intervention, and the benefits of treatment should be balanced against the side-effects and public health impact $[77,90,94]$. Screening for infection seems only warranted when screening and treatment of TB disease are well functioning.

Screening for LTBI was usually carried out via the tuberculin skin test. The more recent interferon- $\gamma$ release assays might be a helpful tool in LTBI screening. A recent systematic review on diagnosis using interferon- $\gamma$ release assays concluded that current evidence suggests that these tests have the potential to become useful diagnostic tools. However, whether this potential can be realised in practice needs to be confirmed in well-designed long-term studies $[95,96]$.

\section{Global investment in TB control}

It was calculated that USA-funded efforts to expand the directly observed therapy strategy programme in Mexico, Haiti and the Dominican Republic could reduce TB-related morbidity and mortality among migrants to the USA, producing net cost savings for the USA [97]. Developed countries will gain most by supporting TB control strategies not only in Europe but also in the rest of the world [74, 86, 97, 98]. Therefore, the ideal long-term TB control strategy remains global investment in TB control [81], in line with the principle of think locally, act globally [86].

\section{SUPPORT STATEMENT}

This study was carried out by the KNCV Tuberculosis Foundation under contract from the European Centre for Disease Prevention and Control.

\section{STATEMENT OF INTEREST}

None declared.

\section{REFERENCES}

1 Falzon D, Belghiti F. Tuberculosis: still a concern for all countries in Europe. Euro Surveill 2007; 12: E070322.1. 
2 Falzon D, Ait-Belghiti F. What is tuberculosis surveillance in the European Union telling us? Clin Infect Dis 2007; 44: 1261-1267.

3 EuroTB and the national coordinators for tuberculosis surveillance in the WHO European Region, Surveillance of tuberculosis in Europe. Report on tuberculosis cases notified in 2006. SaintMaurice, Institut de Veille Sanitaire, 2008.

4 Verver S, Veen J. Tuberculosis control and migration. In: Raviglione MC, ed. Tuberculosis: A Comprehensive International Approach. New York, Informa Healthcare, 2006.

5 Codecasa LR, Porretta AD, Gori A, et al. Tuberculosis among immigrants from developing countries in the province of Milan, 1993-1996. Int J Tuberc Lung Dis 1999; 3: 589-595.

6 Lillebaek T, Andersen AB, Bauer J, et al. Risk of Mycobacterium tuberculosis transmission in a low-incidence country due to immigration from high-incidence areas. J Clin Microbiol 2001; 39: 855-861.

7 Lobato MN, Hopewell PC. Mycobacterium tuberculosis infection after travel to or contact with visitors from countries with a high prevalence of tuberculosis. Am J Respir Crit Care Med 1998; 158: 1871-1875.

8 McCarthy OR. Asian immigrant tuberculosis - the effect of visiting Asia. Br J Dis Chest 1984; 78: 248-253.

9 Ormerod LP, Green RM, Gray S. Are there still effects on Indian subcontinent ethnic tuberculosis of return visits?: a longitudinal study 1978-97. J Infect 2001; 43: 132-134.

10 Borgdorff MW, Nagelkerke N, van Soolingen D, et al. Analysis of tuberculosis transmission between nationalities in the Netherlands in the period 1993-1995 using DNA fingerprinting. Am J Epidemiol 1998; 147: 187-195.

11 Dahle UR, Sandven P, Heldal E, et al. Continued low rates of transmission of Mycobacterium tuberculosis in Norway. J Clin Microbiol 2003; 41: 2968-2973.

12 Diel R, Rusch-Gerdes S, Niemann S. Molecular epidemiology of tuberculosis among immigrants in Hamburg, Germany. J Clin Microbiol 2004; 42: 2952-2960.

13 Coker RJ, Bell A, Pitman R, et al. Screening programmes for tuberculosis in new entrants across Europe. Int J Tuberc Lung Dis 2004; 8: 1022-1026.

14 Harbour R, Miller J. A new system for grading recommendations in evidence based guidelines. BMJ 2001; 323: 334-336.

15 Rieder HL, Zellweger JP, Raviglione MC, et al. Tuberculosis control in Europe and international migration. Eur Respir J 1994; 7: $1545-1553$.

16 Monney M, Zellweger JP. Active and passive screening for tuberculosis in Vaud canton, Switzerland. Swiss Med Wkly 2005; 135: 469-474.

17 Ormerod LP. Tuberculosis screening and prevention in new immigrants 1983-88. Respir Med 1990; 84: 269-271.

18 Callister ME, Barringer J, Thanabalasingam ST, et al. Pulmonary tuberculosis among political asylum seekers screened at Heathrow Airport, London, 1995-9. Thorax 2002; 57: 152-156.

19 Lavender M. Screening immigrants for tuberculosis in Newcastle upon Tyne. J Public Health Med 1997; 19: 320-323.

20 Hardie RM, Watson JM. Screening migrants at risk of tuberculosis. BMJ 1993; 307: 1539-1540.

21 Magkanas E, Drakonaki EE, Voloudaki A, et al. Chest radiography and tuberculosis case-finding in asymptomatic native and immigrant populations in Greece. Int J Tuberc Lung Dis 2005; 9: 865-869.

22 Johnsen NL, Steen TW, Meyer H, et al. Cohort analysis of asylum seekers in Oslo, Norway, 1987-1995: effectiveness of screening at entry and TB incidence in subsequent years. Int J Tuberc Lung Dis 2005; 9: 37-42.

23 Bonvin L, Zellweger JP. Mass miniature X-ray screening for tuberculosis among immigrants entering Switzerland. Tuber Lung Dis 1992; 73: 322-325.
24 Farah MG, Meyer HE, Selmer R, et al. Long-term risk of tuberculosis among immigrants in Norway. Int J Epidemiol 2005; 34: 1005-1011.

25 Netherlands Public Health Service, Flevoland, Midden Brabant Annual Report on Tuberculosis Screening of Asylum Seekers in Reception Centres [Jaarverslag Tuberculose Screening Asielzoekers in Opvangcentra. Flevoland, Midden Brabant]. Utrecht, Netherlands Public Health Service, 2005.

26 Zellweger A, Raeber PA, Desgrandchamps D, et al. Screening for tuberculosis among asylum seekers entering in Switzerland. TSRU Prog Rep 1997; 2: 59-76.

27 Zellweger A. Screening for tuberculosis in risk groups in Switzerland. Bull Bundesamtes Gesundheitsw 1993; 41: 739-742.

28 Keizer S, Annee-van Bavel JACM, Deutekom H, et al., Screening for tuberculosis among immigrants and asylum seekers in the Netherlands: methods and results. Tuber Lung Dis 1994; 75: Suppl. 1, S30.

29 Mathez C, Bangala Y, Bady P, et al. Active screening for pulmonary tuberculosis among immigrants by chest $\mathrm{x}$-ray at the Swiss border. Swiss Med Wkly 2007; 137: 649-654.

30 Flemish Lung and Tuberculosis Association, Tuberculose Opsporing bij Asielzoekers in Belgie, 2004 [Tuberculosis Case Finding among Asylum Seekers in Belgium, 2004]. Brussels, Flemish Lung and Tuberculosis Association, 2004.

31 Markey AC, Forster SM, Mitchell R, et al. Suspected cases of pulmonary tuberculosis referred from port of entry into Great Britain, 1980-3. BMJ (Clin Res Ed) 1986; 292: 378.

32 Laifer G, Widmer AF, Frei R, et al. Polymerase chain reaction for Mycobacterium tuberculosis: impact on clinical management of refugees with pulmonary infiltrates. Chest 2004; 125: 981-986.

33 Bothamley GH, Rowan JP, Griffiths CJ, et al. Screening for tuberculosis: the port of arrival scheme compared with screening in general practice and the homeless. Thorax 2002; 57: 45-49.

34 Van den Brande P, Uydebrouck M, Vermeire P, et al. Tuberculosis in asylum seekers in Belgium. Eur Respir J 1997; 10: 610-614.

35 Harling R, Pearce M, Chandrakumar M, et al., Tuberculosis screening of asylum seekers: 1 years' experience at the Dover Induction Centres. Public Health 2007; 121: 822-827.

36 Ormerod LP. Is new immigrant screening for tuberculosis still worthwhile? I Infect 1998; 37: 39-40.

37 Kesseler K, Maffei D, Meyer FJ, et al. Tuberkulose im Asylsuchenden [Tuberculosis in asylum seekers]. Gesundheitswesen 1995; 57: 670-673.

38 Whitfield RJ, Khan R, Smith A, et al. Current medical treatment for tuberculosis. Resources used for screening could be spent more usefully elsewhere. BMJ (Clin Res Ed) 2003; 326: 550.

39 Breuss E, Helbling P, Altpeter E, et al. Screening and treatment for latent tuberculosis infection among asylum seekers entering Switzerland. Swiss Med Wkly 2002; 132: 197-200.

40 Aerts A, Van de Gucht V, Vansand V, et al. Opsporing van longtuberculose bij asielzoekers in Belgie, 1999-2003 [Tuberculosis screening in asylum seekers in Belgium, 1999-2003]. Tijdschr Geneeskd 2005; 61: 1023-1031.

41 Erkens C, Slump E, Kamphorst M, et al. Coverage and yield of entry and follow-up screening for tuberculosis among immigrants in the Netherlands. Eur Respir J 2008; 32: 153-161.

42 Griffiths C, Sturdy P, Brewin P, et al. Educational outreach to promote screening for tuberculosis in primary care: a cluster randomised controlled trial. Lancet 2007; 369: 1528-1534.

43 Valin N, Antoun F, Chouaid C, et al. Outbreak of tuberculosis in a migrants' shelter, Paris, France, 2002. Int J Tuberc Lung Dis 2005; 9 : 528-533.

44 Wilcke JT, Poulsen S, Askgaard DS, et al. Tuberculosis in a cohort of Vietnamese refugees after arrival in Denmark 1979-1982. Int J Tuberc Lung Dis 1998; 2: 219-224. 
45 Underwood BR, White VL, Baker T, et al. Contact tracing and population screening for tuberculosis - who should be assessed? J Public Health Med 2003; 25: 59-61.

46 Rivas-Clemente FP, Nacher-Conches M, Corrillero-Martin J, et al. [The results of an active screening program for tuberculosis in immigrants from the Maghreb: acceptability and adherence]. Aten Primaria 1999; 24: 411-416.

47 Kuyvenhoven JV, Lambregts-van Weezenbeek CS, Annee-van Bavel JA. Tuberculose bij asielzoekers in Nederland [Tuberculosis in asylum seekers in the Netherlands]. Ned Tijdschr Geneeskd 1997; 141: 581-584.

48 Bwire R, Verver S, Annee-van Bavel JA, et al. Dekkingsgraad van tuberculosescreening bij immigratie: sterke afname bij vervolgscreening [Tuberculosis screening coverage of immigrants: marked attrition in follow-up screenings]. Ned Tijdschr Geneeskd 2001; 145: 823-826.

49 El-Hamad I, Casalini C, Matteelli A, et al. Screening for tuberculosis and latent tuberculosis infection among undocumented immigrants at an unspecialised health service unit. Int J Tuberc Lung Dis 2001; 5: 712-716.

50 van Burg JL, Verver S, Borgdorff MW. The epidemiology of tuberculosis among asylum seekers in the Netherlands: implications for screening. Int J Tuberc Lung Dis 2003; 7: 139-144.

51 Laifer G, Widmer AF, Simcock M, et al. TB in a low-incidence country: differences between new immigrants, foreign-born residents and native residents. Am J Med 2007; 120: 350-356.

52 Scolari C, El-Hamad I, Matteelli A, et al. Incidence of tuberculosis in a community of Senegalese immigrants in Northern Italy. Int $J$ Tuberc Lung Dis 1999; 3: 18-22.

53 Tuberculosis in the Netherlands. Tables 2005 [Tuberculose in Nederland 2005, tabellen]. The Hague, KNCV, 2005. www. kncvtbc.nl/Site/Components/SitePageCP/ShowPage.aspx?ItemID= c2739d3a-8f52-482b-8d01-b55e09edf2ed\&SelectedMenuItemID = 2588b0df-6a8f-4c37-9a96-4e6811c834c4\#PageTemplate:Content TemplateHolder:ContentHolder_4 Date last accessed: August 25, 2009.

54 van Loenhout-Rooyackers JH. Risico van tuberculose bij inadequate opvang van aspirant-asielzoekers [Risk of tuberculosis in the inadequate handling of refugees seeking asylum]. Ned Tijdschr Geneeskd 1994; 138: 2496-2500.

55 Garcia de Olalla P, Cayla JA, Mila C, et al. Tuberculosis screening among immigrants holding a hunger strike in churches. Int $J$ Tuberc Lung Dis 2003;7: Suppl., S412-S416.

56 Kamphorst-Roemer M. Screening for non-BCG vaccinated immigrants 12 to 25 years of age for tuberculosis in Rotterdam. Community Health Physician Training Thesis, Municipal Health Service, Rotterdam, 2004.

57 Rysstad OG, Gallefoss F. TB status among Kosovar refugees. Int J Tuberc Lung Dis 2003; 7: 458-463.

58 Fernandez Sanfrancisco MT, Diaz Portillo J, Sanchez Romero JM, et al. Tuberculosis infection prevalence among the immigrant population in Ceuta, Spain. Rev Esp Salud Publica 2001; 75: 551-558.

59 Smith A, O'Flanagan D, Igoe D, et al. Outcome of medical screening of Kosovan refugees in Ireland: 1999. Commun Dis Public Health 2000; 3: 291-294.

60 Rivas Clemente FP, Nácher Conches M, Corrillero Martín JC, et al. Prevalencia de infeccion tuberculosa entre los inmigrantes magrebies [Prevalence of tuberculosis infection in Maghrebian immigrants]. Med Clin (Barc) 2000; 114: 245-249.

61 Ormerod P. Issues facing TB control (1.1). Tuberculosis in United Kingdom immigrants/organisation of tuberculosis control services. Scott Med J 2000; 45: Suppl., 22-23.

62 Erkens C, Slump E, Verver S. Monitoring Screening van Immigranten (MSI) Cohort 1998-2002 Vervolgd t/m 2005 [Monitoring of Screening of Migrants: Cohort 1998-2002 Followed-up until 2005]. The Hague, KNCV Tuberculosis Foundation, 2007. www.kncvtbc.nl/site/
Components /FileCP / Download.aspx?id =0d9c8846-ac0b-49e38f4f-52c5b55d64ee Date last accessed: August 25, 2009.

63 Flemish Lung and Tuberculosis Association, Tuberculose Opsporing bij Asielzoekers in Belgie, 2003 [Tuberculosis Case Finding among Asylum Seekers in Belgium, 2003]. Brussels, Flemish Lung and Tuberculosis Association, 2003.

64 Flemish Lung and Tuberculosis Association, Tuberculose Opsporing bij Asielzoekers in Belgie, 2002 [Tuberculosis Case Finding among Asylum Seekers in Belgium, 2002]. Brussels, Flemish Lung and Tuberculosis Association, 2002.

65 Tuberculose in Nederland 2003-2004 KNCV, Tabellen [Tuberculosis in the Netherlands 2003-2004, Tables]. The Hague, KNCV, 2003. www.kncvtbc.nl/Site/Components/SitePageCP/ShowPage.aspx? ItemID $=c 2739 \mathrm{~d} 3 \mathrm{a}-8 \mathrm{f} 52-482 \mathrm{~b}-8 \mathrm{~d} 01-\mathrm{b} 55 \mathrm{e} 09 \mathrm{edf2ed} \&$ Selected MenuItemID =2588b0df-6a8f-4c37-9a96-4e6811c834c4\#Page Template:ContentTemplateHolder:ContentHolder_4 Date last accessed: August, 25: 2009.

66 Plant AJ, Watkins RE, Motus N, et al. Results of tuberculosis screening in applicants for migration in Vietnam and Cambodia. Int J Tuberc Lung Dis 2005; 9: 157-163.

67 Bwire R, Nagelkerke N, Keizer ST, et al. Tuberculosis screening among immigrants in the Netherlands: what is its contribution to public health? Neth J Med 2000; 56: 63-71.

68 Heldal E, Dahle UR, Sandven P, et al. Risk factors for recent transmission of Mycobacterium tuberculosis. Eur Respir J 2003; 22 637-642.

69 Cooke G, Hargreaves S, Natkunarajah J, et al. Impact on and use of an inner-city London Infectious Diseases Department by international migrants: a questionnaire survey. BMC Health Serv Res 2007; 7: 113.

70 Norredam M, Mygind A, Krasnik A. Access to health care for asylum seekers in the European Union - a comparative study of country policies. Eur J Public Health 2006; 16: 286-290.

71 Morrison J, Pai M, Hopewell PC. Tuberculosis and latent tuberculosis infection in close contacts of people with pulmonary tuberculosis in low-income and middle-income countries: a systematic review and meta-analysis. Lancet Infect Dis 2008; 8: 359-368.

72 Bothamley GH, Ditiu L, Migliori GB, et al. Active case finding of tuberculosis in Europe: a Tuberculosis Network European Trials Group (TBNET) survey. Eur Respir J 2008; 32: 1023-1030.

73 Inigo J, Arce A, Rodriguez E, et al. Tuberculosis trends in Madrid, 1994-2003: impact of immigration and HIV infection. Int J Tuberc Lung Dis 2006; 10: 550-553.

74 Inigo J, Garcia de Viedma D, Arce A, et al. Analysis of changes in recent tuberculosis transmission patterns after a sharp increase in immigration. J Clin Microbiol 2007; 45: 63-69.

75 Coker R, Bell A, Pitman R, et al. Tuberculosis screening in migrants in selected European countries shows wide disparities. Eur Respir J 2006; 27: 801-807.

76 Lillebaek T, Andersen AB, Dirksen A, et al. Persistent high incidence of tuberculosis in immigrants in a low-incidence country. Emerg Infect Dis 2002; 8: 679-684.

77 Dasgupta K, Menzies D. Cost-effectiveness of tuberculosis control strategies among immigrants and refugees. Eur Respir J 2005; 25 1107-1116.

78 French CE, Antoine D, Gelb D, et al. Tuberculosis in non-UK-born persons, England and Wales, 2001-2003. Int J Tuberc Lung Dis 2007; 11: $577-584$.

79 Menzies D. Tuberculosis crosses borders. Int J Tuberc Lung Dis 2000; 4: Suppl., S153-S159.

80 Maloney SA, Fielding KL, Laserson KF, et al. Assessing the performance of overseas tuberculosis screening programs: a study among US-bound immigrants in Vietnam. Arch Intern Med 2006; 166: 234-240.

81 Dasgupta K, Schwartzman K, Marchand R, et al. Comparison of cost-effectiveness of tuberculosis screening of close contacts and foreign-born populations. Am J Respir Crit Care Med 2000; 162: 2079-2086. 
82 Ruggles R, Young Y, Rayner CF. Contact tracing and population screening for tuberculosis - who should be assessed? J Public Health Med 2003; 25: 391-392.

83 Farah MG, Tverdal A, Steen TW, et al. Treatment outcome of new culture positive pulmonary tuberculosis in Norway. BMC Public Health 2005; 5: 14.

84 Kim DY, Ridzon R, Giles B, et al. A no-name tuberculosis tracking system. Am J Public Health 2003; 93: 1637-1639.

85 Heldal E, Kuyvenhoven JV, Wares F, et al. Diagnosis and treatment of tuberculosis in undocumented migrants in low- or intermediateincidence countries. Int J Tuberc Lung Dis 2008; 12: 878-888.

86 Cain KP, Mac Kenzie WR. Overcoming the limits of tuberculosis prevention among foreign-born individuals: next steps toward eliminating tuberculosis. Clin Infect Dis 2008; 46: 107-109.

87 Dahle UR. Compulsory screening of immigrants for TB and HIV: screening could detect latent infection. BMJ (Clin Res Ed) 2004; 328: 897.

88 Walter ND, Jasmer RM, Grinsdale J, et al. Reaching the limits of tuberculosis prevention among foreign-born individuals: a tuberculosis-control program perspective. Clin Infect Dis 2008; 46 : 103-106.

89 Porco TC, Lewis B, Marseille E, et al. Cost-effectiveness of tuberculosis evaluation and treatment of newly-arrived immigrants. BMC Public Health 2006; 6: 157.
90 Coker R, Lambregts-van Weezenbeek CS. Mandatory screening and treatment of immigrants for latent tuberculosis in the USA: just restraint? Lancet Infect Dis 2001; 1: 270-276.

91 Cain KP, Haley CA, Armstrong LR, et al. Tuberculosis among foreign-born persons in the United States: achieving tuberculosis elimination. Am J Respir Crit Care Med 2007; 175: 75-79.

92 DeRiemer K, Chin DP, Schecter GF, et al. Tuberculosis among immigrants and refugees. Arch Intern Med 1998; 158: 753-760.

93 Zuber PL, Binkin NJ, Ignacio AC, et al. Tuberculosis screening for immigrants and refugees. Diagnostic outcomes in the state of Hawaii. Am J Respir Crit Care Med 1996; 154: 151-155.

94 Menzies D. Screening immigrants to Canada for tuberculosis: chest radiography or tuberculin skin testing? CMAJ 2003; 169: 1035-1036.

95 Pai M, Menzies D. The new IGRA and the old TST: making good use of disagreement. Am J Respir Crit Care Med 2007; 175: 529-531.

96 Pai M, Riley LW, Colford JM Jr. Interferon- $\gamma$ assays in the immunodiagnosis of tuberculosis: a systematic review. Lancet Infect Dis 2004; 4: 761-776.

97 Schwartzman K, Oxlade O, Barr RG, et al. Domestic returns from investment in the control of tuberculosis in other countries. $N$ Engl J Med 2005; 353: 1008-1020.

98 Suk J, Manissero D, Büscher G, et al. Wealth inequality and TB elimination in Europe. Emerg Infect Dis 2009; (In press). 